\title{
Christian Kalin
}

\section{Verhaltensnorm und Kollisionsrecht}

Eine Studie zu den rechtsgeschäftlichen Auswirkungen der Korruption im internationalen Rechtsverkehr

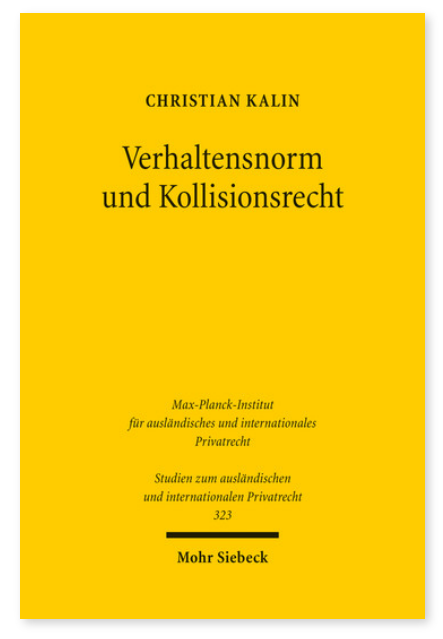

2014. XIX, 279 Seiten. StudIPR 323

ISBN 978-3-16-153613-7

DOI 10.1628/978-3-16-153613-7

eBook PDF 79,00€

ISBN 978-3-16-153612-0

fadengeheftete Broschur 79,00€
Der zunehmenden Bedeutung der grenzüberschreitenden Korruptionsbekämpfung hat der deutsche Gesetzgeber durch eine beträchtliche Ausweitung strafrechtlicher Sanktionsdrohungen Rechnung getragen. In zivilrechtlicher Hinsicht sind indes allein die diesen normtheoretisch vorgelagerten Verhaltensnormen - insbesondere als »gesetzliche Verbote« - von Bedeutung. Unter konsequenter Beachtung der Einheit der Rechtsordnung untersucht Christian Kalin das komplexe Zusammenspiel in- und ausländischer korruptionsbezogener Verhaltensnormen sowohl im privatrechtlichen wie auch im strafrechtlichen Kontext. Dabei entwickelt er ein normtheoretisch begründetes, differenziertes kollisionsrechtliches Anknüpfungssystem, welches neben der Heranziehung von Verhaltensnormen als gesetzliche Verbote auch eine abgeschwächte Beachtung ausländischer Verhaltensnormen innerhalb eines kollisionsrechtlichen Subsystems zu erklären vermag und so ein neues Licht auf die traditionelle Problematik der Eingriffsnormen wirft.

Christian Kalin Geboren 1983; Studium der Rechtswissenschaften in Passau; seit 2010 wissenschaftlicher Mitarbeiter an der Universität Passau; seit 2014 Rechtsreferendar im OLG-Bezirk München.

Jetzt bestellen:

https://mohrsiebeck.com/buch/verhaltensnorm-und-kollisionsrecht-9783161536137?no_cache=1

order@mohrsiebeck.com

Telefon: +49 (0)7071-923-17

Telefax: +49(0)7071-51104 